\title{
DETERMINING THE FIRST PRIORITY OF THE FIRST ARSENAL LOCATION TO SUPPORT THE OPERATION OF THE INDONESIAN WAR SHIP IN SECURITY OF THE EASTERN INDONESIAN SEA REGION WITH AHP
} METHODS

\author{
I Nengah Putra $A^{1}$, Sukmo Hadi Nugroho ${ }^{2}$, Okol Sri Suharyo ${ }^{3}$, Cahyanto ${ }^{4}$ \\ ${ }^{1}$ Indonesia Defense University, Unhan Jakarta Indonesia \\ ${ }^{2}$ Esa Unggul University, Jakarta Indonesia \\ 3, 4 Indonesian Naval Technology College, STTAL, Surabaya Indonesia
}

\begin{abstract}
Faced with conditions of life of the nation that continues to evolve into a multidimensional cover all areas of life of the nation, then certainly required the development and deployment of the total potential and power of the nation effectively. Therefore it is the power that was developed to deal with these threats must also have the ability to multi-dimensional as well. Reality is always pushing to restructure the military concept of defense to become responsive and adaptable and tailored to the substance of the reforms in the defense. The main problem faced by Indonesia to develop a domestic defense industry is the inability of industry and education sectors to absorb the fundamental aspects of the Revolution in Military Affairs (RMA). This inability does not allow Indonesia to experience significant breakthroughs in the application of RMA. So with reference to the condition necessary to anticipate concrete steps in developing a systematic plan to build the defense industries are able to anticipate the revolution in military affairs. Among priorities at once by selecting the appropriate stages of the development plan which includes the development of Main Equipment Weapon System, Spatial Planning Area Defense, Civil Defense Development, and Spatial Structure of the Organization. And one of its efforts is the creation of the ability of military logistics support system effective and efficient and responsive, which in this case is the development of Arsenal's arsenal of weapons and ammunition in terms of both quality and quantity so that is always ready to face any condition of any contingency that would happen. Determining policy location Arsenal first location contains more choices in environmental issues multiobjectiv and multicriteria decision, then the model is proposed to be the appropriate methodology to accommodate the qualitative preference and priority-setting objectives / criteria for future development is to approach the Analytical Hierarchy Process (AHP). Principle of the AHP method is to break breaking a complex situation and unstructured, into its component parts, arranging these variables in a section or an order of hierarchy, giving numerical values to subjective considerations about the relative importance of each variable and analysis various considerations is to determine which variables have highest priority and act to influence the outcome of the situation. From the results of the solution by using AHP method showed that the first priority location determination Arsenal 1 in the eastern region is a factor analysis of logistics operations to support operations capabilities in integrated logistics support system that effectively and efficiently. And the locations selected for Arsenal's first priority location is in the eastern region Lantamal Ambon.
\end{abstract}

Keyword: Determining location - Approach of the Analytical Hierarchy Process (AHP)

\section{INTRODUCTION}

\subsection{Background}

The strength of the Navy is strongly influenced by several components, such as the structure of strength, the level of readiness, the level of sophistication or sophistication of the technology and the sustainability of the operations of the Alutsista owned. The synergy of the four components of strength is largely determined by the ability of the state to build and maintain the capabilities of the defense system. The Indonesian Warship (KRI) as one component of the Integrated
Fleet Weapon System (SSAT) is a vital force in the forefront of Indonesian defense to guard the maritime territory of the Unitary Republic of Indonesia (NKRI) with all its interests. And the direct correlation of the increase in defense equipment certainly must be balanced between the level of needs and the ability of support so that it can directly improve operational capabilities in the field. Where unit operational readiness can only be done optimally if supported by the availability of logistics optimally. And one of them was through the role of weapons logistics support and 
ammunition from Arsenal to meet the needs of KRI. The direct operational role in supporting the needs of weapons and ammunition in the Navy in storing, maintaining and distributing is under the Office of Weapons and Electronics of the Navy (Dissenlekal), namely Arsenal. Some of the functions of Arsenal according to the Decree of the Indonesian Navy Chief (KASAL) Number: Kep / 31 / VII / 1997 are compiling plans for the development of weapons materials including general weapons, special weapons, and ammunition including facilities and infrastructure, preparing a plan of needs and proposal for procurement material in the framework of helping Kadissenlekal compile plans for the needs of weapons and ammunition of the Indonesian Navy, carry out reception and storage activities both in the context of refilling warehouses and returns from user units. If Arsenal is able to optimize the existing logistics system both in terms of service, maintenance, organization and distribution support, it is expected that the country's defense capability at sea will be improved. Determining the location of Arsenal warehouses has a strategic role, how, where and where needs to be served is the main focus in determining the location, because strategic locations can directly increase the speed of service and be able to reduce logistics distribution costs.

\subsection{Research Purposes}

This research is conducted by aiming at the objectives to be achieved, namely as follows:

a Determine the Priority criteria for the right Arsenal location first so as to be able to support the placement and development of a class $\mathrm{V}$ logistics distribution system for $\mathrm{KRI}$ in the operational mandala. b. Making a decision-making model in determining the location of the First Arsenal with the AHP method in the eastern region.

\subsection{Research Methodology}

The thing that is done by a researcher or writer before research is to always determine the approach that is considered most appropriate to the problem to be solved. Then, there are several issues that are located on the issue of efficiency, namely the limitations of funds, labor, time and capabilities of the researcher. The research method used in this research is qualitative methodology. The data collection techniques are as follows:

a. Observation, make a direct observation of the object of research in this case the Arsenal institution as the person in charge of management and distribution of Navy Class $V$ logistics supplies, namely logistical weapons and ammunition.

b. Interviews, carried out to official officers who have expertise competencies and problems in the placement of arsenal positions and questionnaire data which are the perceptions of respondents.

c. Document Analysis, analyze documents relating to location determination and AHP method.

d. Literature Study, using references related to Location Theory, Logistics Theory, Decision Making Theory, and AHP Method.

\section{MATERIAL AND METHODS}

The stages that need to be done in the research will be described in a research framework which is then called the research methodology. In this study using the AHP method so that the optimal alternative decision is expected to be produced. 


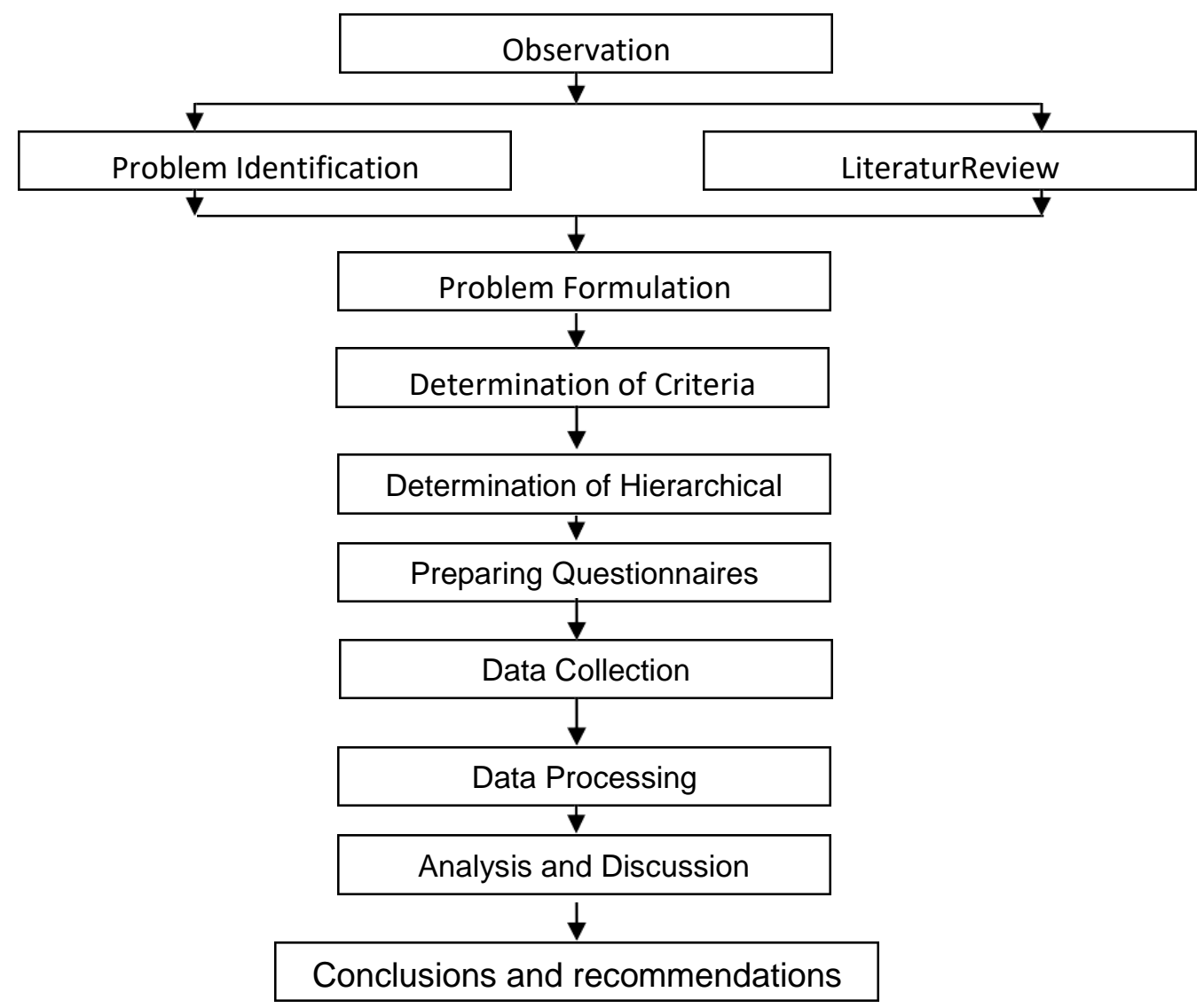

Fig.1 Research Flow Chart

\subsection{Observation and identification of} problems

At this stage it aims to understand the concepts related to the Ammunition Distribution System, where the problem of optimization of support services is the main consideration in obtaining effective and efficient operational support, especially to uncover existing constraints and to achieve the attainment of the Navy's force towards the Minimum Essential Force standard. Many obstacles faced in the distribution of ammunition are mainly due to considerations of distance, space and time of service so that it is highly deemed necessary to deal with evolving and rapid environmental changes. Arsenal do not have Arsenal warehouses in other areas that can support the smooth distribution of supplies. Class V stock warehouses scattered in the operating area are only warehouses owned by units in the area and only very limited capacity and only for the sake of the unit itself are not to be distributed to other operating units. Arsenal are concentrated in one place (Batuporon, Madura) and there is no other unit that synergizes and integrates organizationally with Arsenal in terms of class $\mathrm{V}$ provision support, when faced with a very wide area of operation besides raising the length of the distribution net, it also creates its own vulnerability. continuity of stock support. With the placement of the location of Arsenal 1 , it is expected that the distance to the support logistics base is relatively close so that the need for logistical support is easier to implement, especially for the operating area in the eastern region.

\subsection{Literature review}

Literature study is an assessment of the literature of books, journals and previous research related to the concept of defense strategy, Defense 
Policy, Posture and Defense doctrine of the Indonesian Armed Force, military logistic system and study of distribution of ammunition in operations and AHP methods along with tools used for analysis and improvement in system.

\subsection{Problem Formulation}

Formulation of the problem is the basis of the implementation of research activities, because here the core problem can be known with certainty and the method of completion and the means used have been identified. The formulation of the problem in this study is how to prioritize the location of first arsenal in eastern Indonesia.

\subsection{Determination of Criteria}

In this activity, solving and decomposing the problem into small components. Where the method of determining criteria and sub criteria is taken based on the results of literature studies and interviews. In addition, it is also done by studying references - references in the form of appreciation and conception of the development of Arsenal and references to Arsenal standardization, which then results are used as a reference in breaking down the elements of the criteria up to alternatives that can be chosen as decisions. Seeing from the many determinants of the location of the arsenal, the researchers tried to bring the problem solving closer using the AHP method so that in the end from the number of decision variable variables the highest weight value can be obtained representing the alternative choice of the expected location.

\subsection{Determination of Hierarchical Structure}

Components of the problem resulting from decomposition are then arranged in a hierarchy. The first step is to identify the levels and elements that will be placed on a level. Then all the levels and elements are defined and used in the question formulation stage, where concepts, questions and answers to answers determine the elements and levels of a hierarchy. At this stage it is a decisive step where uncertainty or errors in the process of answering questions will make the decision makers choose the wrong criteria and alternatives, therefore all questions should be answered and consistent with the existing information as a support for achieving the validity and efficacy of the model in the future.

\subsection{Preparing Questionnaires}

After the hierarchy has been formed then we must first ascertain whether the prospective respondent already understands and approves the form of hierarchy that has been made. For data input this questionnaire is used to fill the comparison matrix that is the comparison between element elements in one level by considering the influence of elements on the level above. Comparison is carried out on a scale of one to nine and fulfills AHP axioms.

\subsection{Data Collection}

Data collection is done by defining primary and secondary data. Secondary data is obtained by collecting from various literature or reference books, journals, analyzing expert analysis, documents etc., then collecting primary data is through interviews with official officers who have expertise competencies and problems in the placement of Arsenal positions and questionnaire data which are perceptions respondents were conducted by distributing questionnaires.

\subsection{Data Processing}

Data processing is done systemically where in processing data is arranged in steps as follows: 


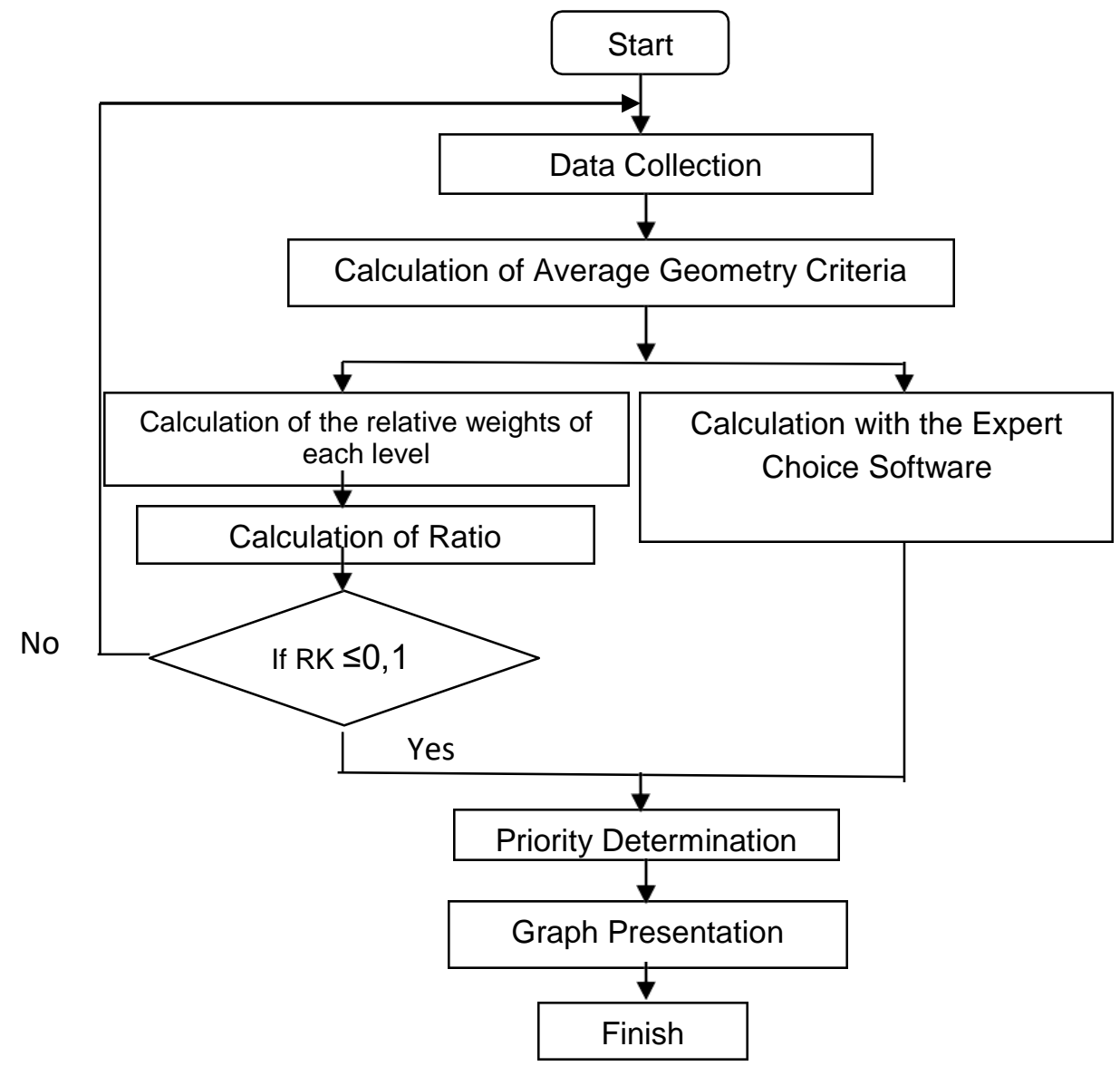

Fig.2 Data Processing Steps

\subsection{Sensitivity analysis}

Used to anticipate changes in weight and parameters, sensitivity analysis is carried out. This change occurs when the decision maker changes the weight / parameters of a criterion due to input that makes the criteria not so important. In addition, these changes can occur because after a time it turns out that there is a change in wisdom. This is useful to determine the extent to which these changes can affect the results that have been obtained.

\subsection{Analysis of results}

At this stage, an analysis of the results of data processing using the AHP method and sensitivity analysis will be conducted so that priority location selection alternatives can be determined to support suggestions for objective and rational decision making in decision making.

\subsection{Conclusions and Suggestions}

In this section the results of the study will be concluded and further recommended to the Indonesian Navy leadership in the selection of alternative locations for Arsenal 1 in eastern Indonesia.

\section{RESULT AND DISCUSION}

\subsection{Analysis of Strategic Environmental Development}

Referring to the dynamics of strategic environmental developments and consideration of the geographical constellation of Indonesian waters to support the plan to build the Navy's strengths, integrated and harmonious planning is needed, including by choosing priorities as well as appropriate stages of development plans which include the development of the Weapon System Main Tool, Spatial Planning Defense, Civil Defense Development, and Structuring Organizational 
Structure. Geography Indonesian waters which have high complexity due to the influence of two continents and two oceans need to be broadly classified. This classification is needed to determine the types of defense equipment that are suitable for local water conditions and thus, the overall needs of the Indonesian Navy's defense equipment can be determined. With the selection of the location of the construction of weapons logistics and ammunition support facilities in Ambon as in the results of the study, this shows that Ambon has overall strategic advantages towards the logistical support system for improving the ability of the $\mathrm{KRI}$ in the operational mandala so that more effective and efficient operations are maximized.

\subsection{Sensitivity Analysis}

The assessment process carried out in this study is based on analytical process methods, where judgment is done by judgment. Where respondents are directly involved in the problem formulation process and the respondent has a large contribution in determining the location and requirements. The assessment results processed in the AHP processing are the average of ten respondents obtained by the repetitive process. This repetition aims to provide a consistent assessment, and on the other hand respondents increasingly have an understanding of the research process. The final data processed has a consistent category, this can be observed from the value of the risk of the consistency of the valuation that does not exceed the value of $10 \%$. This analysis is done using the sensitivity graph display on the results of data processing using Exsper Choice software, with the aim of knowing the conditions facing each other between criteria and sub criteria. Where the purpose of this analysis is as an illustrative basis for changes related to shifting weights / priorities which will later be accommodated and influence the results of the Navy's decisions / policies, in this case the determination of the priority of the first
Arsenal location in the eastern region. Change of weight / priority technically can be done as we want by shifting the graph scale. Simultaneously there will be a change in both the weight / priority values and the priority order.

\subsubsection{Sensitivity analysis for level 2 (criteria) Determination of the first Arsenal Priority Location in Eastern Indonesia.}

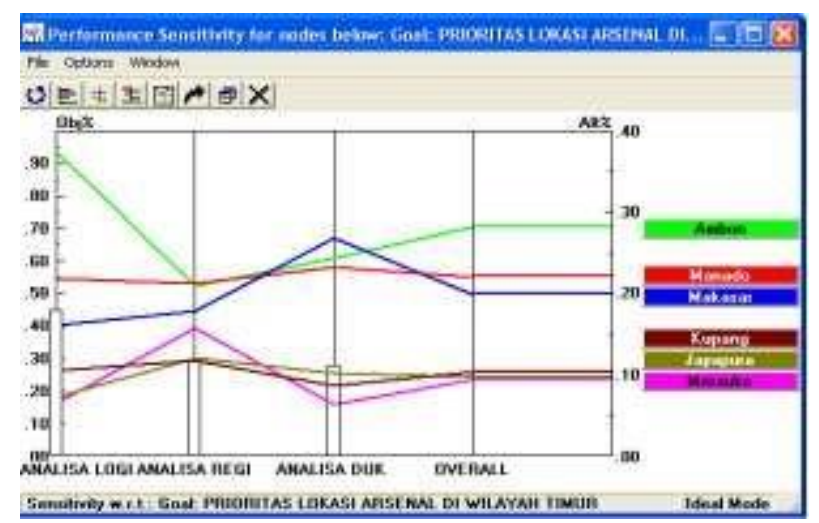

Fig.3 The graph of the sensitivity of the destination criteria

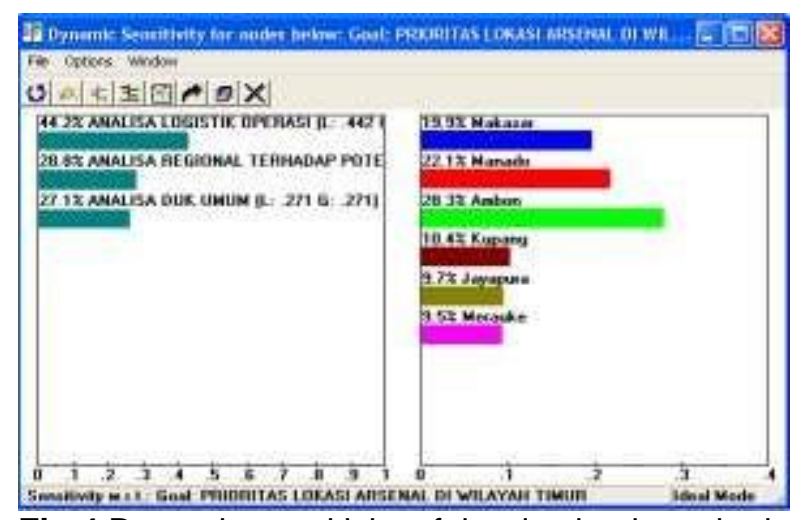

Fig.4 Dynamic sensitivity of the destination criteria

Assessment of AHP processing results on the aspect of level two criteria in determining the location of Arsenal was obtained that the analysis of operational logistics obtained the highest value of $44.2 \%$ compared to the analysis of potential threats of $28.8 \%$ and general supporting analysis of $27.1 \%$. From the calculation results, it is obtained the order of priority locations namely Ambon amamal region, followed by sequential lanterns of Manado, Makasar, Kupang, Jayapura and Merauke. The level of difference in value here is included at a 
significant level so it can be concluded how big the priority of logistics analysis is to influence factor values other criteria. By looking at the growth rates of both the economy, politics and defense, especially the estimated economic rate, escalating threats and the level of fulfillment of defense budget needs per year, the authors take an average increase of about $15 \%$ as a trial of priority weight changes that can be used as a minimum reference to the potential potential of criteria for determining the priority of Arsenal's location ahead, although it does not guarantee that it is always that big, but can be used as a scenario test for estimates and considerations of alternative location choices according to the needs and leadership policies of the sensitivity graph obtained in this study. Then try on each of the scenario criteria to be raised and lowered according to the leadership's desires and policies, and on the sensitivity graph scale the operating logistic analysis criteria if we make a weight change of $15 \%$, at the operating logistical graph value 0.59 , the potential threat is 0.14 and general support 0.27 , then the results of alternative location options obtained at Lantamal Ambon, whereas if lowered $15 \%$ obtained value of 0.29 in the analysis of operational logistics, potential threats of 0.37 and general supporters of 0.34 , the results of alternative location options remain in Lantamal Ambon. For changes in the value of weights in the sensitivity analysis of potential threats that can change the alternative choices, the probability is small. Where the results of the scenario of changing weights increase by about $15 \%$, it is very small to be able to, change the position of the choice of Ambon. At the operating logistical graph value 0.35 , the potential threat is 0.43 and the general supporter is 0.22 , the alternative location of the alternative is obtained at Lantamal Ambon. Whereas for changes in weight values in the general supporting sensitivity analysis around $15 \%$, the logistic analysis weight value is
0.33 , threat potential 0.25 and general support 0.42 priority results are fixed location on alternative options for Ambon ammunition. This shows that Ambon has a strategic value, especially in terms of changes in sensitivity both for policy opportunities, priority for each aspect of the criteria, both for current and future policies so that it can be used as a top priority reference for the future.

3.2.2 Sensitivity analysis for level 3 (subcriteria) Determination of the first Arsenal Priority Location in Eastern Indonesia from Operational Logistics Analysis.

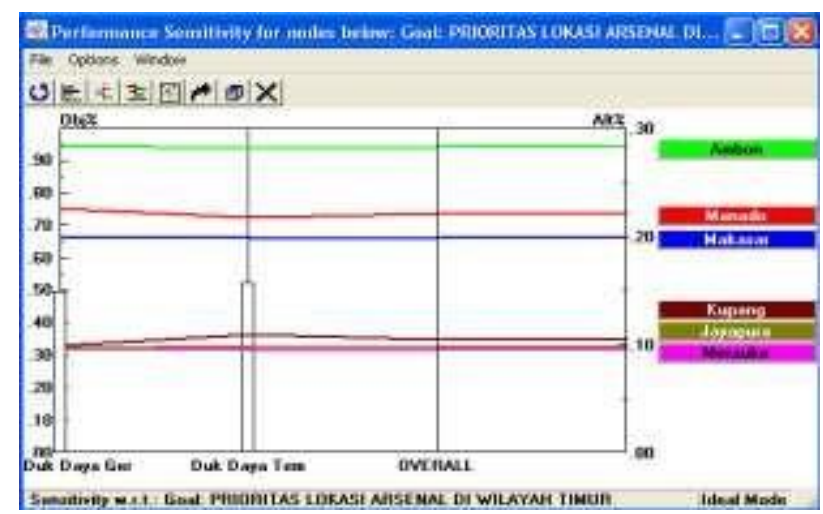

Fig.5 Graph Performance sensitivity of Operational Logistics Analysis criteria

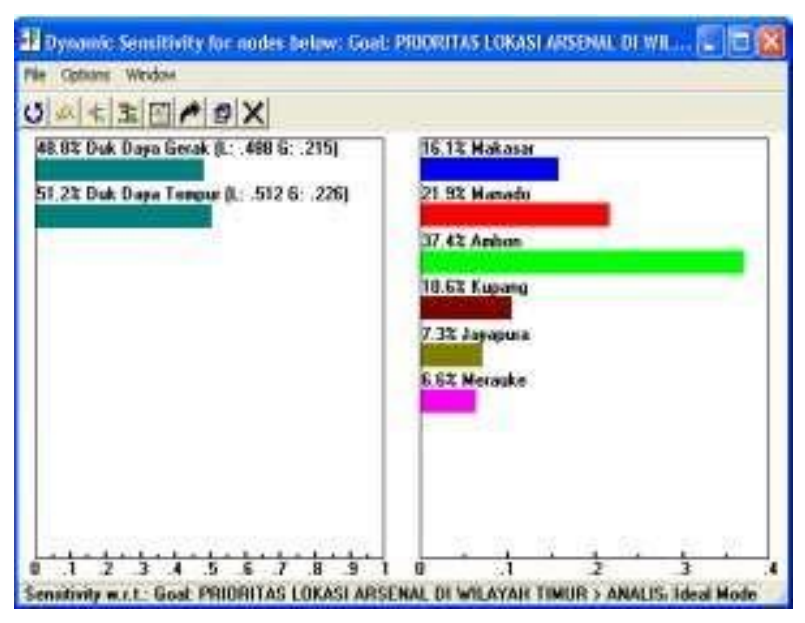

Fig.6 Dynamic sensitivity Sub Operational Logistics Analysis Criteria

For the results of the weighting of the objective criteria from the operating logistic analysis factor, it was scored $44.2 \%$. And the results of the processing of the sub-criteria which are the parts 
given by the respondents in the logistic operating factor analysis, respondents tend to provide an almost balanced assessment of both the sub criteria of motion and combat power. Where the consideration of the value of motion is $48.8 \%$ and combat power is $51.2 \%$. This assessment was given based on the consideration that with the vast coverage area and operating sector for the KRI throughout the eastern region, where the location tends to be far from one another, Arsenal's main priority as a source of logistical support, especially in relation to distribution systems for weapons and ammunition, must be balanced so that KRI in carrying out its functions can run optimally. Among them is the effectiveness of the range of sources of logistics for the operating area capable of providing benefits in terms of distance, time and providing timeliness of support so as to be able to support combat resistance and continuous operation. After conducting a sensitivity test on the graph of the results, it was found that Ambon alternative locations remained the highest even though changes in priorities were carried out both in terms of mobility and combat power, this shows that it is indeed appropriate that Ambon's location is the main choice where first Arsenal is held.

\subsubsection{Level 3 sensitivity analysis (sub-criteria)} Determination of the first Arsenal Location Priority in Eastern Indonesia from Regional Analysis of Potential Threats.

Where from the four threat sub-criteria available, it is found that for the location feasibility, the order of priority for feasibility in the form of marine security threats, regional border threats, the threat of social unrest and the hardest is the threat of terrorism. Because basically the definition of the potential threat criteria here is the extent to which the danger level is chosen and which one is feasible to build.

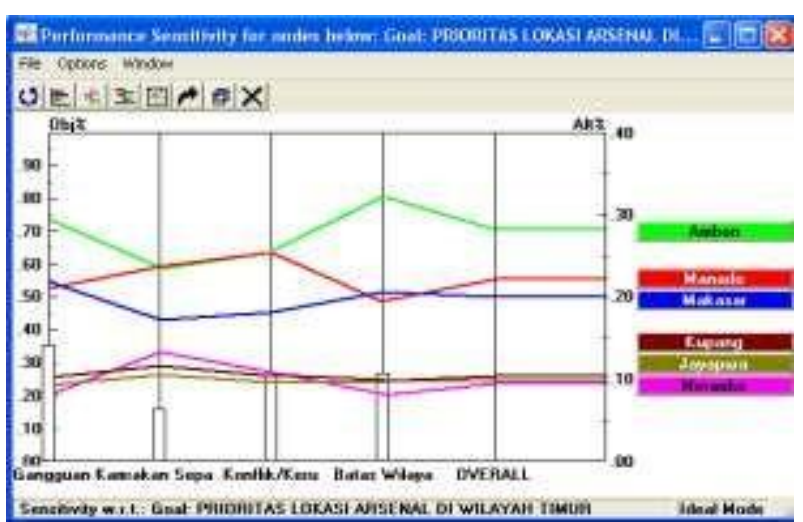

Fig.7 Performance graphs of sensitivity criteria for Regional Analysis Potential Threats.

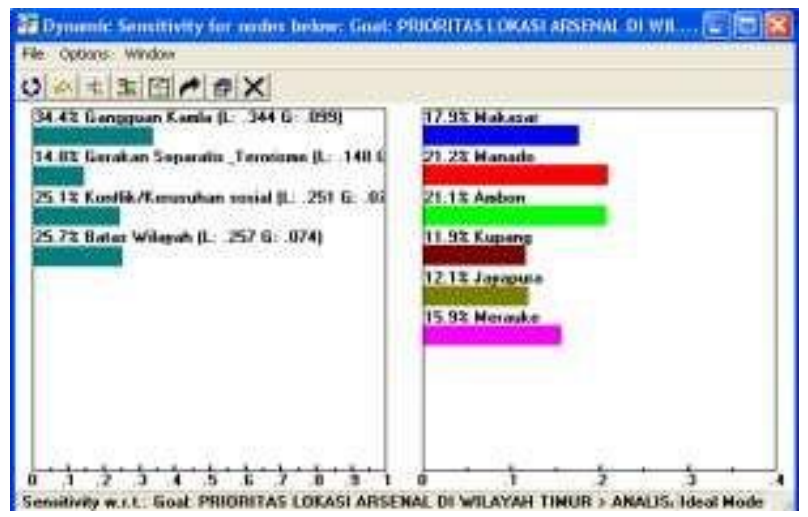

Fig.8 Dynamic sensitivity Analysis of threat potential in each sub-criteria

For the results of the weighting of the objective criteria from the operating logistic analysis factor, the score was $28.8 \%$. And the results of the processing of the sub-criteria which are the parts given by respondents in the operating logistic analysis factor, obtained the sub-criteria of marine security threats (34.4\%), separatist threats and terrorism (14.8\%), for threats of conflict and social difficulties $(25.1 \%)$ and for the threat of regional boundaries amounting to $(25.7 \%)$ with the priority order of locations being Manado (21.2\%), followed by Ambon (21.1\%), Makassar (17.9\%), Merauke ( $15.9 \%)$, Jayapura (12.7\%) and Kupang (11.9) which means that respondents tend to provide an assessment of the threat aspect that by taking into account the level of vulnerability and the risk of threat threats that exist, the lightest value that gives consideration The main factor in determining the location is the factor of marine security, then new 
regional borders, the level of social unrest and finally the factor of terrorism threat. This factor is certainly not an absolute thing, where it can be adjusted to the conditions that exist in Manado and Ambon almost the same so that it can be used as an alternative location choice if the decision makers at one time prioritize the importance of potential hazards compared to the analysis of operational logistics.

\subsubsection{Level 3 sensitivity analysis (sub-criteria)} Determination of the first Arsenal Priority Location in Eastern Indonesia from General Support Analysis.

Fig.9 Graph of performance sensitivity General Support Analysis criteria
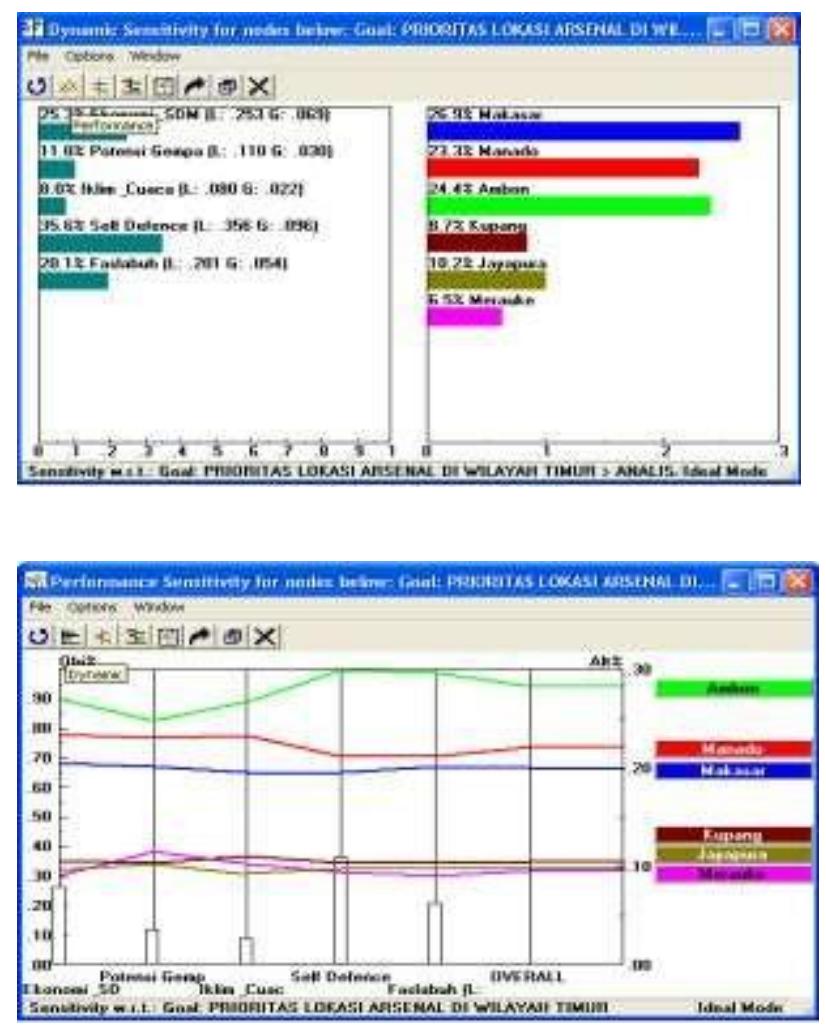

Fig.10 Graph of Priority Values for General Support Analysis in each Sub-Criteria.

For the criteria of supporting factors, the score of $27.1 \%$ is obtained by prioritizing subcriteria, namely as the first order is the factor of selfdefense ability (35.6\%), economy \& HR (25.3\%),
Port Facility (20.2\%), Earthquake potential (11.0\%) and Iklin \& weather (8\%). This means that in determining the location of Arsenal from the existing sub-criteria factor, it turns out that the ability factor of the alternative location of the arsenal and ammunition from the protection and deterrence of threats from inside and outside is a top priority compared to the others. the main is Lantamal Ambon, Ambon's strength here because of the location of the area surrounded by other territorial areas, where the ability of protection will certainly have double strength, so that before the threat threatens the Ambon area and enters then it must pass the existing defense area, either by land, sea or air. But locally the priority of order choice obtained is that Makassar Lantamal (26.9\%) is mainly affected by the level of economic growth but the disadvantage of Makassar is that the integration of Arsenal 1's location remains directly related to the main Arsenal where Makassar location is quite close to the main Arsenal in Surabaya. So that from the results of the analysis globally that for the sake of the continuity of Arsenal's development in the future, of course Ambon Lanterns must continue to improve, especially in improving the economy and HR better. according to the priority order that economic strength and capability and human resources as objects of organizational actors occupy the second number after the ability to protect themselves.

\subsection{Technical Analysis of Data Processing Processes}

In the results of data processing there is a small difference in the results of calculations between the use of software using Microsoft Excel, this is due to the rounding of numbers behind the comma, but for the order of priority results are the same. To get results that are closer to the similarities of the two methods can be done by avoiding the rounding of numbers behind the 
comma. But rhetorically the AHP method with the calculation of Microsoft Excel is in accordance with the rules in the AHP method. As the final result in the data processing the researcher used the results reference from the processing using the Exspert choice software which had high accuracy besides also giving a lot of information about things as well as possible possibilities that could occur related to the decision maker in giving priority to the criteria criteria.

\section{CONCLUSION}

a In military operations, logistics cannot be separated from military operations, because without good planning and logistical support, military operations cannot be carried out. Based on the research using the AHP method, the criteria that are the top priority in determining the location priority of Arsenal 1 are logistical analysis criteria for operations, while the global weight of the highest priority sub-criteria is combat power sub criteria. This means that Operational Logistics is the main consideration for determining the location of Arsenal's arsenal, which is expected to be able to increase the support of logistics services effectively, efficiently and responsibly and be able to increase the ability of elements of the KRI in the field of operations to safeguard the sovereignty of the Nation and State.

b. As for the results of the decisionmaking method, the priority order of the location of the research results is obtained to prioritize the location of the first Arsenal in Eastern Indonesia.

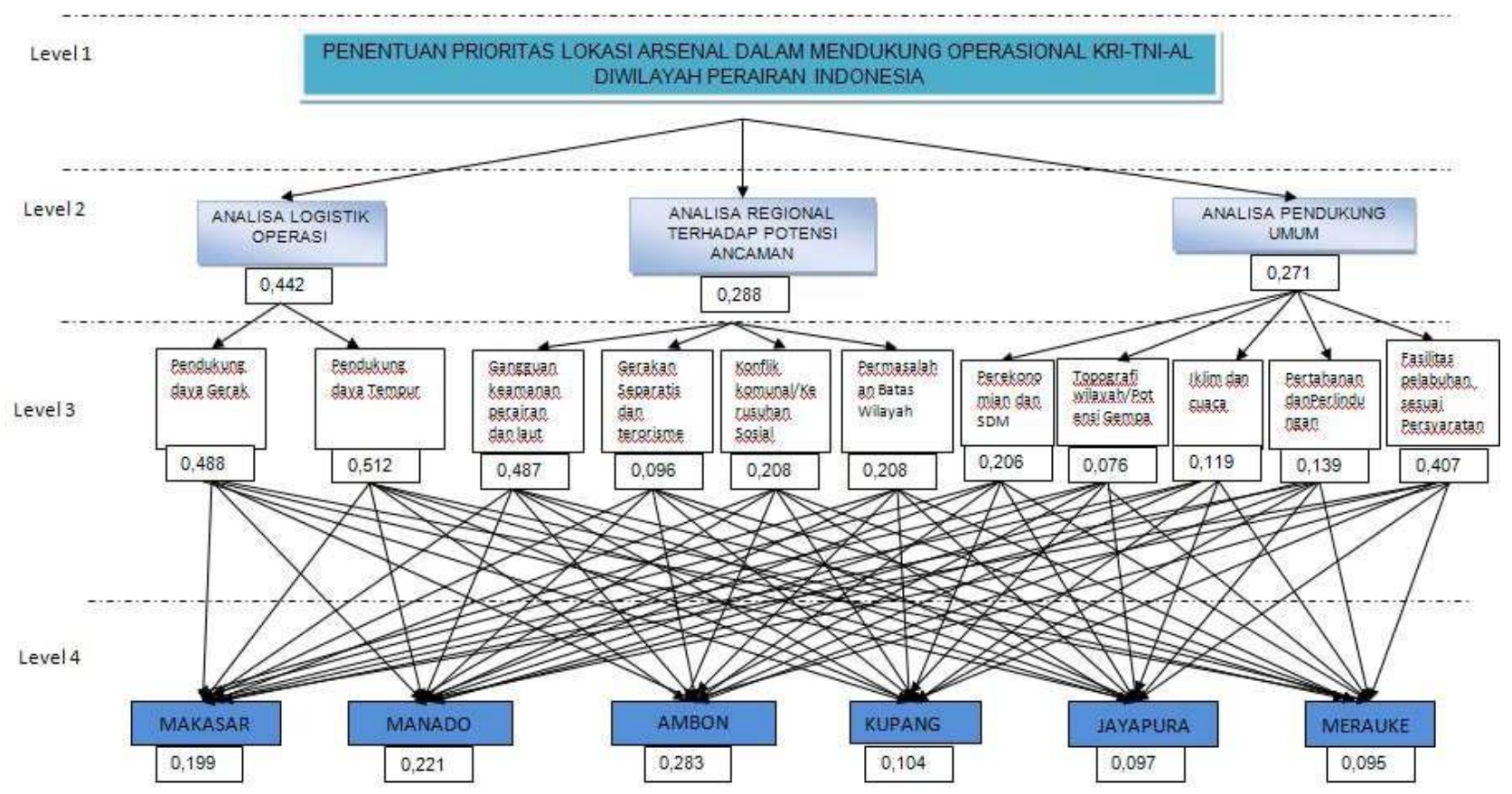

Fig.11 Results of AHP Processes

Table 1. Order of Location Priority Weights for Prtama Arsenal.

\begin{tabular}{|c|c|c|}
\hline No & Alternative location & Priority Weight \\
\hline 1 & Ambon & 0,283 \\
\hline 2 & Manado & 0,221 \\
\hline 3 & Makasar & 0,199 \\
\hline 4 & Kupang & 0,105 \\
\hline 5 & Jayapura & 0,097 \\
\hline 6 & Merauke & 0,095 \\
\hline
\end{tabular}




\section{REFERENCES}

Bowersox, Donald J. Logistics Management 1 and 2, Systems integration, Physical distribution management and material management.

Elwood S Buffa, 1987. Modern Production Operations Management, Erlangga Publisher Jakarta.

Exspert Choice Inc., 2000, Exspert Choice second Edition, Info @ ExspertChoice.com2002.

Edi S Binandita.2008. Analysis of Determination of Biodesel Plant Location From Coconut as an aspect of alternative energy source review in East Java using the Electre III method, Surabaya, Final Project of STTAL Bachelor 2008.

Fernandez, P. Dr. Cosmas, SVD, MA, Empowerment of defense areas through joint discussions with all components of the nation in order to support national interests.

Logistics World, 1996, Logistix Parteners OY, Helsinki Fl,

Navy General Publication (Log-003,306) concerning the Manual for Administrative Procedures for Warehousing in the Navy. SKEP / 999 / IV / 1998 number.

Nurharyoko, Gogor, 2008, Strategic Review of the RI defense strategy concept,

President of the Republic of Indonesia, 2002, Law of the Republic of Indonesia No. 3 of 2002 concerning State defense, Jakarta 2002 and enhancement of the ability of national defense, (chapter 7).

Priyambodo, Kakung, 2004. Determination of the priority location of the strength of the responsive maritime unit in the deployment of forces in eastern Indonesia by the AHP method (STTAL final project), Surabaya.

Purwokuncoro, Didong Rio Duta, 2002, Determination of Priority Development of Indonesian Navy Base in the area of he East Kawsana Fleet command by the AHP method, Surabaya, STTAL Bachelor Final Project 2002.
Regulation of the Minister of Defense Number: Per / 22 / M / Xii / 2007, About, Republic of Indonesia's National Defense Strategy, Number: Per / 23 / M / XII / 2007, About the Republic of Indonesia's National Defense Doctrine.

Ramdhani, Ali. 1997, Determination of Housing Priority based on the merging of the Promethee and AHP Method, Master's Thesis, ITB Postgraduate Program.

Saaty, Thomas L., 1993, Decision Making for leaders,Jakarta, PT. Binindo Persindo Library 1991.

Saaty, Thomas L., 1994, Fundamentals of Decision Making and Priority Theory with Analyticalcal Hierarchy Process, The Analitycal Hierarchy Process Series Vol.VI. RWS Publications, Pittsburg.

Salusu, J. 1991, Strategic Decision Making for Public and Non-profit Organizations, Jakarta, PT Gramedia Widiasarana Indonesia 1996.

Sjafrizal, Regional Economic Theory, concepts and development, EKI. Jakarta in 1983.

Suryadi, Kadarsah, 2000. (p. 138). Decision Support System for an Idealist Structural Discourse and Implementation of Decision Making Concepts, PT Remaja Rosdakarya Bandung.

Tarigan, R, 2004, Regional Economics, theory and application. Bumi Aksara Jakarta.

The Department of Defense's Strategic Product 2008, concerning Indonesian Defense Doctrine, Strategy, Policy and Posture.

Waluyo Hidayat, Bambang, (Wee Chow-Hoo, Lee Khai Shang, Sun Tzu, War and Management), PT Elex Media Kompetindo, Jalan Palmerah Selatan 23 JKT 10270).

Wignjosoebroto, S.2003. Introduction to Industrial Engineering \& Management, First Edition, Guna Widya Publisher, Surabaya. 